Questionnaire: SP (2001-02)

Target Group: SPs 1+

RESPIRATORY HEALTH AND DISEASE - RDQ

\begin{tabular}{ll|}
\hline & BOX 1 \\
CHECK ITEM RDQ.005: & \\
IF SP AGE < 12, GO TO RDQ.070. \\
OTHERWISE, CONTINUE
\end{tabular}

RDQ.030 \{Do you/Does SP\} usually cough on most days for 3 consecutive months or more during the year?

\begin{tabular}{|c|c|}
\hline 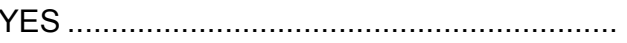 & 1 \\
\hline NO .................. & 2 (RDQ.050) \\
\hline REFUSED ....... & 7 (RDQ.050) \\
\hline DON'T KNOW . & 9 (RDQ.050) \\
\hline
\end{tabular}

RDQ.040 For how many years \{have you/has SP\} had this cough?

IF LESS THAN 1 YEAR, ENTER 1

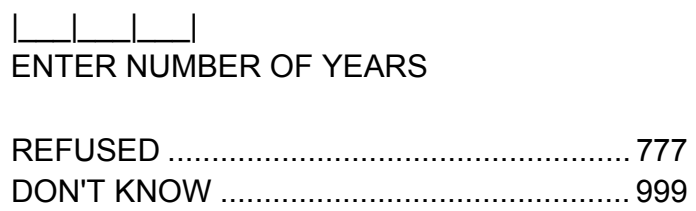

RDQ.050 \{Do you/Does SP\} bring up phlegm on most days for 3 consecutive months or more during the year?

\begin{tabular}{|c|c|}
\hline YES .... & 1 \\
\hline NO .... & 2 (RDQ.070) \\
\hline REFUSED ........ & 7 (RDQ.070) \\
\hline DON'T KNOW & 9 (RDQ.070) \\
\hline
\end{tabular}

RDQ.060 For how many years, \{have you/has SP\} had trouble with phlegm?

IF LESS THAN 1 YEAR, ENTER 1

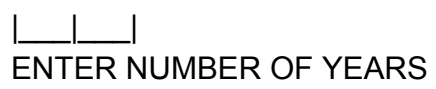

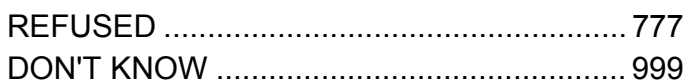

RDQ.070 In the past 12 months $\{$ have you/has SP\} had wheezing or whistling in $\{y o u r / h i s / h e r\}$ chest?

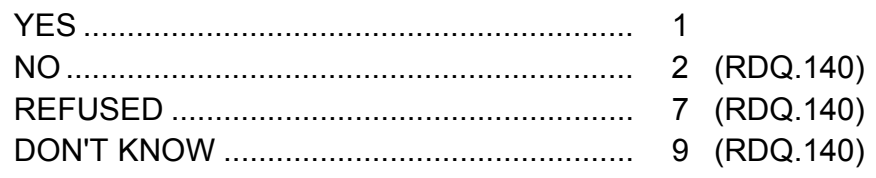

RDQ.080 [In the past 12 months], how many attacks of wheezing or whistling \{have you/has SP\} had? IF 12 OR MORE EPISODES, ENTER 12

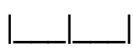




\section{ENTER NUMBER OF EPISODES}

REFUSED ……….................................. 77

DON'T KNOW ........................................... 99

RDQ.090 [In the past 12 months], how often, on average, has \{your/SP's\} sleep been disturbed because of wheezing? Would you say this happens...

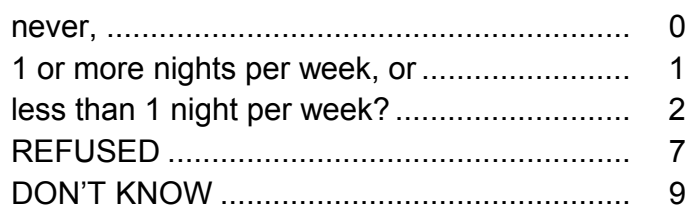

RDQ.100 [In the past 12 months], has \{your/SP's\} chest sounded wheezy during or after exercise or physical activity?

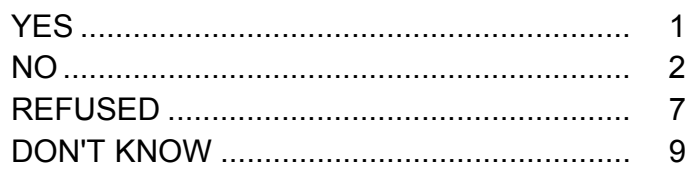

RDQ.120 [In the past 12 months], how many times \{have you/has SP\} gone to the doctor's office or the hospital emergency room for one or more of these attacks of wheezing or whistling?

IF NEVER, ENTER 0

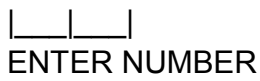

REFUSED …................................... 77

RDQ.134 [In the past 12 months], \{have you/has SP\} taken any medication, prescribed by a doctor, for wheezing or whistling?

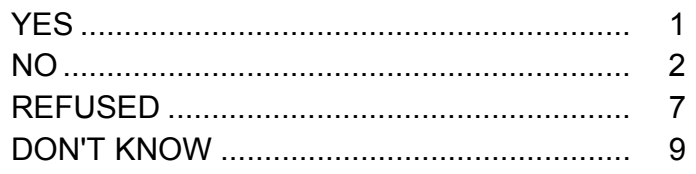

RDQ.135 During the past 12 months, how much did $\{y o u / S P\}$ limit $\{y o u r / h i s / h e r\}$ usual activities due to wheezing or whistling? Would you say...

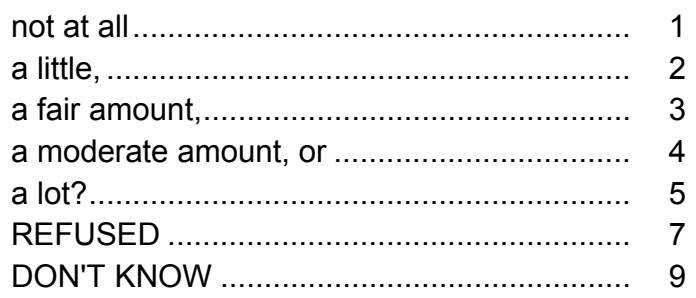

\section{BOX 4}

CHECK ITEM RDQ.136:

IF SP AGE = 6-69 YEARS, CONTINUE.

OTHERWISE, GO TO RDQ.140. 
RDQ.137 During the past 12 months, how many days of work or school did \{you/SP\} miss due to wheezing or whistling?

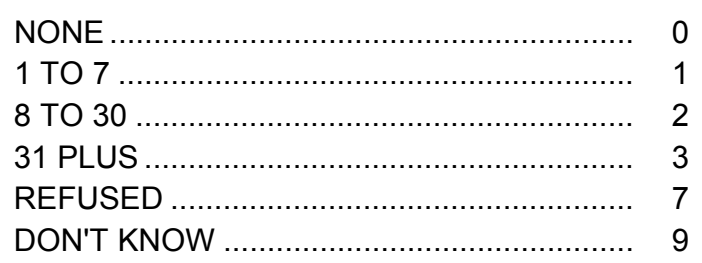

RDQ.140 [In the past 12 months], \{have you/has SP\} had a dry cough at night not counting a cough associated with a cold or chest infection lasting $\mathbf{1 4}$ days or more?

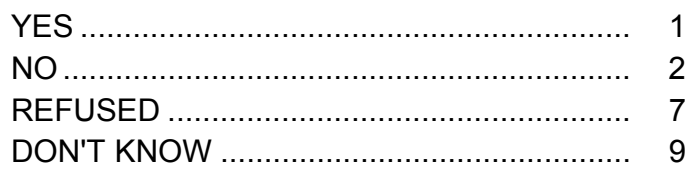

